\title{
Creative Thinking in Fashion Deconstruction
}

\author{
Nining Tristantie ${ }^{1}$ \\ \{nining.t@gmail.com\}
}

State University of Medan, Medan, Indonesia ${ }^{1}$

\begin{abstract}
Creative industri one of it is fashion is a backbone filled with steadily ideas creation requiring and competetitive dinamic innovation offering. Fashion is built through fashion design creative process to initiate bright idea will be accepted by market. The essence of fashion design is creativity. Creativity, Artistic as well as Innovation aim at how originally an object is built conceptually or through design. Creativity implies world new introductory but not for performing an existing design. Fashion design is claimed to represent new elements or genuin solution for problems for globalized competetive. The presence of deconstrucism is a contemporary culture which stipulates novelty and contemporary. Deconstrucism is a fashion style which displays strong fashion character which contains statement and high originality. Deconstructivism represents different attitude in work, represents fashion which has strong concept and character as a differentiator of other fashion that displays revolutionary fashion as every work has colementnfrontative collection. Through library research, ideas exploration and fashion design creation find creative construction to gain essential aspect in the creative process to prepare visual which contains 'novelty' in it. The Aspect and chategory discussed are manners that is prosecuted in fashion work deconstrucism.
\end{abstract}

Keywords: Creative, fashion, design, deconstructivism

\section{Introduction}

Creativity in the fashion design is crucially needed especially in creating artistical product that has market value. [15]. However, the problem of creativity is still a main issue and a central issue in developing creative industry in Indonesia [3]. This issue is derived from trade industry as a significant problem in gaining competition of artistic product relates to quality human resource among countries [16].

Creativity, culture and education is pictured as a future capital [2]. The creative industry capability in encountering the crisis based on the creativity globality and innovation making product design by noticing opportunities [17]. As having done by China, Globalization is anticipated by emphasizing on creative economic basic by preparing strategies such as massive improvement on national fashion industry concept [17]. Creative design, innovation and technology are the backbones which is described as two wheels that intensely support the future transitition on fashion design sector as a creative fashion design scope which should be advanced positioned [8].

Fashion design lies on basic principles and pratices to make creative process logically by preparing frame work to improve the skills. One of the stages in fashion design is pointing out the creative design process which successfully applied to fullfill the market needs by considering trends and posessing problem solving [10]. These are need to support the students 
to develop the inovation and experiments which will be a portrait of indicators which influent the fashion activity development in fashion learning to be adapted in the contemporary fashion industry [13]. The strength of character offered in the contemporary design is the novelty factor and deconstrucism problematic assumed as solution for creativity problems in fashion design learning.

Deconstruction is an architecture concept adopted into fashion idea which has contemporary aesthetic, unique and has strong concept during its process. Deconstruction is one of the most important in phenomenon in the world of fashion. Designers were forced to look back, consider and discover the visual elements used [19].

Deconstruction is usually desribed as one of trends which changes rapidly in one mode. The discussion of architectural philosophy theory which is seen from alternative perspective theory - Michel de Certeau and John Fiske's conception. This theory is used to glance at decostructions and its important aspect in contemporary fashion design.

Challenging in deconstruct design has an essence of beauty naturally and emphasizes on the accuracy of stereotypical popular structure. Disordered method is quickly recognized by society and draws interest fashion practitioners attention and welcomed by acceptance through some arising critics. Deconstrutivation replication is getting new design from its original form to release from modernism standard as it was stilted, clean and simple. Contrasting from those, deconstrucism offers new design tends to be spoiling, incomplete, overlapped, separated from all and not integrated in a unity in which design elements apply edge pieces, repetition and translucent effect in the creative process [18].

\section{Methodology}

\subsection{Creativity Problems in Fashion Design}

Working in Fashion_needs high creativity, time racing, competitive competitiveness to be a trendsetter [7]. Creativity and innovation which uphold originality is not negotiable, as working in fashion industry is susceptible in plagiarism carried out in a large scale. Before immitation is widen, fashion designer must send forth new design to offset the economic loss. Bringing up creation to be uptodate is a must for a fashion design [5]. It requires the fashion creator to improve better innovation thru creative thinking. It is time for education to reform the learning methode by encouraging the students to ask from 'know - why' and finally become 'know - how'. The roots of creative society is basic education by leaving out old thinking not as a technician but as a visioner by using creativity, culture and education.

The characteristics of creativity always involve thinking or behaving imaginatively. Second, overall this imaginative activity is purposeful: that is, it is directed to achieving an objective. Third, these processes must generate something original. Fourth, the outcome must be of value in relation to the objective.

Creative idea could come up by appearing problematic found in the daily life in the context of social, politics and culture. The next stage is seeking on some facts or reality related to inovative and creative ideas. The accuracy of thinking power and focusing on issu which is raised to find its solution is challenging for students in finishing up an issue. The final result is a perfect concept and brilliant idea [12]. Essentially, learners are invited to be able to explore not only the ideas but also to find character in each design quality.

Stressing on the objective in fashion design fasilitated by characteristics of fine arts elements of fashion deconstructivism, it is a learning substantive for creativity research and 
appropriated innovation by integrating effective activity of learning. The application of deconstructivism characters could be standards of design understood by learners carried out thru informative research from central issues resource in making practical concept.

The importance of integration either theory or practical concept of deconstructivism in fashion design learning theoritically should be taught as a productive learning. The use of deconstructivism motivates students to actively participate with theoritical ideas from textual resources and apply these concepts in fashion designing concept [4]. The use of deconstructivism aims on how to motivate students to be innovative and creative designer [11].

\subsection{Process of Creative Fashion}

Like other theory of art and design, fashion has close relationship with theory and scientific method which involves creative design process in creating shelf reflection pattern of cultural practice. Theory of perception and reflection are parts of creative process and design format, universally visual, refer to observed cases. Though during its creative process ideas finding and thought are made on contingency context, but these do not mean creative process has no method. Complicated value concept in art or fashion are not transsfered from objects of self contemplation performer; in fact it is negotiated or mediated by communicative ways [11].

Communication is not manifested in one way but is based on mutual interactions among designers, objects and performers. Fashion (like art) combine creative technique and innovative process as well as social exchange potential. It is served as a internal point of view, developing reflection from original practices of the creator (artist, designer) - as well as a $n$ external point of view, as a social role, aesthetic or culture [1].

Creativity problematic is discovered in the routines as in example, an attempt to immitate something, the result could be a like. It would be very different if someone does a diversity by doing variation and combination which finally lead someone to create an object which is call 'novelty' [14]. Evaluation on creativity is made based on value substancy derived from accurate analisys in giving response thru visual communication on 'feel/sense' of the creativity object. Artistic creative design or innovation, aims at created objects based on originality, conceptualiy and designs. Being creative means to familiarize the word new objects, on the other hand but showing off the emanated design. New elements or genuine solution are requested. The main factor of innovation is how a creative process influence genetically innate, environment, where someone revolt, it trigger a scientific revolutionary upheavel. Human creativity is generated by using dicotomy between rational such as left brain knowledge as intuitive and imaginative are on the right brain, which both need requiring combination to execute the innovation.

\section{Result and Discussion}

\subsection{Deconstrucism on Fashion}

Decontrtucism is a philosophical dialectic emerges at design study. This concept arises in the fine art periodecally stages. Modernism is an answer of questions inquired by fine artists and practitioners of Art and Design problematics. Refusal of modernism is based on rigid visual form, clean, novelty concept acceptance and up todate known as contemporary. 
Unusual pattern and confrontative on a deconstrucvism fashion design is an issue which has novelty value in the study of contemporary aesthetic.

One of the concept of deconstrucism in the process context is 'breaking' by producing a 'cut-off' look or application of pointed hemlines, folding stocks, are unusual stiches, unfinished material expose which then is revalued as considered consumen products. Fashion design brings provocation and excitement, fear and homesickness. Deconstructivism makes problematic dualism between anesthesia and emotional innovation.

Deconstrucism allocates emotion attaches on fashion traditional system, load breaking relationship and traditional statistics. Isolating constuctive element by deconstructing shape and fuctions into individual components. Overall, it is an approach to structural destruction. Conventional visual is a pile of different material, space and construction harmoically come up as collages or mess or disorder. Deconstructivism fashion design work dismantles standard aesthetics and observers are puzzled and enjoying on how the turmoil is rearranged coincidentally.

On the other side concept of deconstructivism design apply recycled products which stresses on aesthetic elements rather than ecologically consideration. Sewing technique could apply creation become pattern technic.

In the field of fashion design study, the deconstructivism approach is believed to bring changes to creative and innovative ways of thinking, especially in processing visual elements that lead to the creation of creative scissors techniques (Creative Cutting Technic) in addition to varied styling [1].

Deconstructivism Design has a contemporary aesthetic that emphasizes design work that is subjective in nature. In fashion studies this can help students to create new, imaginative elements that have implications for creativity and innovation. The demand for fashion design education in general is that each fashion learner is able to bring personal character to the design concept so that it has what is called the signature style.

\subsection{Deconstructivism problems}

Derrida's Deconstruction Application as a method of creation has its own consequences. As explained earlier, to avoid a single meaning, deconstruction provides an appreciation of diversity, exploration of unregulated ideas and techniques so that elements of novelty are easy to obtain. But the consequence is that the communication aspect becomes less achievable because communication requires the same interpretation of meaning so that the message is easily understood [9].

As a solution, Derrida's deconstruction is done partially so that the elements of novelty and communicative aspects can be achieved at once [6]. If then there is an assumption that the application of deconstruction will definitely produce anti -esthetic work, in fact it is a difference in understanding the definition of aesthetics. The aesthetic philosophy of each era and culture is certainly different. What is modernized as beauty by modernists is in fact contrary to postmodernists.

In the design of art and architecture, structure and form are subject to 'destruction' and new construction in the sense of deconstruction, reconstruction and transformation. In this case the user is no longer oriented to functions that emphasize clothing construction. The user's vision of construction has shifted and made this understanding an important part. Traditional understanding. The deconstruction approach to fashion makes all these important and interesting things more visible, where shapes become more important than color. Acceptance of aesthetic concepts related to body proportions and criteria of beauty has shifted by questioning again 


\subsection{Creative and Innovative in Deconstructivism}

The goal of fashionable creativity in the alteration of the human body as a form of awareness of visual illusions towards human figures. The only main factor for fashion design is by using the shape of the human body as a reference to produce the best, "super superative forms also rise to superlative attention" [11]. This expression is a reality that designers commonly do for centuries in and the appearance of fashionable clothing is considered mandatory. Until now the adaptation of fashion creation with this tradition is still inherent, fashion is created to achieve the goal of perfection. Awareness of this perfection traditionally does not allow conflicting forms to become part of fashion. The design orientation is usually to correct less than perfect proportions. This is called Body Conciousness.

Deconstruction is a process that requires solving tradition, which is a rethinking of old ideas and reconfiguring of the old form. Deconstructivism questions the part of clothing that is considered fixed (fixed) but still needs to be questioned in other words 'not finished'. Traditional understanding of dress aesthetics is understood to be able to be observed through the completion of clothing that must meet the standard criteria set, such as the form of clothing that reflects body conciousness, proper finishing, to the completion of clothing details such as neat stitch edge accuracy. If there are unfinished finishes, silhouettes that do not refer to what is called an ideal body image, this condition for traditional understanding is considered a threat to dressing aesthetics. On the contrary for the understanding of deconstructivism, this is considered as deconstructing the aesthetics of the perfection of dress.

Traditional system design puts a combination such as a pattern or material that is assembled and draped on the body having a combination that is in line with the demands of ideal perfection of body shape. This principle is different in the design of Deconstructivism, which actually emphasizes the opposite. Form assembly and use of used materials is unusual. The forms used tend to use disproportionate or even excessive sizes. The main goal is to express the personal character of the designer about problems with themes from the environment, social, cultural, ultimately creating provocation in visualization representations. In the end this design has a personal, original character. The concept of thinking has been triggered by Avant-Garde thinkers who argue that through the creative process and work, it will produce a new dictionary of designs that are expected to be able to challenge existing norms and attitudes aimed at creating a new visual language of clothing that is able to express a designable personality. It is anti-rationalistic and implies an intuitive world view; it aims at individual solutions that are specific to every object; uniqueness instead of mass production; organic forms; toleration of neglect and wear; corrosion and contamination used to intensify the expression; ambiguity and contradiction; suitability being less important. Beauty can be enticed out of ugliness [17].

\subsection{Form - Overform - Deform -Multiform}

Form is a concept of fashion construction made with a traditional system with awareness of Body Conciousness for the achievement of perfection. This concept overform tends to use a form that has a disproportionate size. Adding more size is extended from the normal shape, the initial shape is shifted so as to create the illusion of an abnormal shape. For example, the addition of certain parts that visually impress 'defect', due to the addition of shoulder pads. Or excessive attitude in exploring body shape. In this case the designer does not question the function of clothing in general. The function here is considered complete. Clothing structure is not disturbed by functional considerations, Clothing in this context is overformed by blurring the function of clothing to the point of immobility. 
Deformation. The boundary between overforming and deformation is always changing. This concept rearranges the normal body shape so that it transmits the form not only at the level of overforming but has deformed the body, thus changing the overall figure of the human body. To strengthen this concept, it is supported by the use of textiles that are deformed in the form of 'so that it creates a deconstruction of the human body. The breakthrough about the concept of the body itself is carried out with a cubism approach by resembling it and using it again in a different way for character textiles. At this stage the body shape becomes fictitious, Kawakubo responds between an ideal and unrealistic figure leading to body fiction.

Fiction is mainly seen as elemental and postmodernist pretensions. Some deconstructivist designers process the concept of overforming more, but present poetically. As Kawakukbo's work questions the acceptance of imperfection, and the direction to traditional thinking about fashion, he repeatedly rejects the beautiful, noble and perfect concept by continuing to experiment with forms by creating two body silhouettes, bringing fashion designs closer to sculpture.

\subsection{Multiform}

The concept of deconstruction design is a process that develops from the previous process of deformation. A designer's intelligence with a combination of genius and the idea of creating a fashion form that is far from the formal law of clothing that produces imaginative forms such as the Organic form.

\subsection{Organic Form}

Formal law of clothing follows classical aesthetics and postulates of balanced proportions far exceeding organic forms and morphology. Morphological structure is considered as irregularity, or even as a provocation of this concept of clothing by departing from the previous concept. The creation of fashion can achieve a hyperstructured form of clothing itself. In these creations, the 'development' process appears to visually use overlapping lines, use of cross-linked materials or loss of stitches in knit patterns that cause open loops to appear holes so that organic patterns are created, resulting in forms innovative. The designer in this case does not aim to give decoration or has intentional elements to decorate.

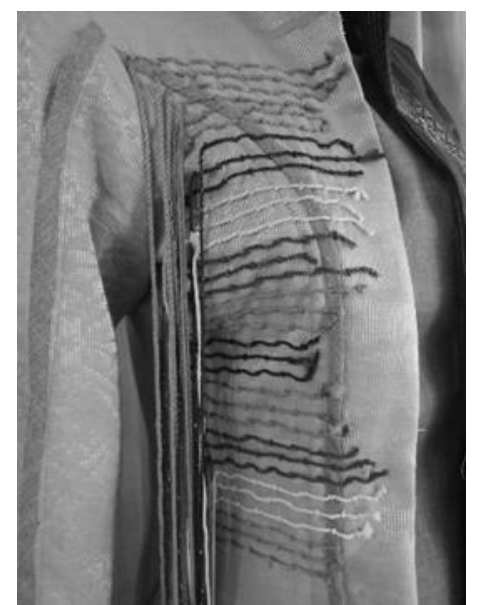

Fig. 1. The work of student's Deconstruction, reconstruction the normal arm into detail body shape 


\subsection{Fixation.}

The other form of design in deconstructivism is still a reinterpretation of the initial function which was previously used by time. This shift in the function of clothing is a critical form of thinking in criticizing the function of clothing if it carries a central issue.

Innovation in fashion is by breaking down understanding, thinking logic that is free of doubts to bring up unusual ideas. Fashion design generally moves in recycling circles. The meaning is that fashion is currently in the formal law of repeating what happened in the past to be presented at this time with a few changes made to it. Simply put, a little innovation is done on it. But in the design of deconstruction, innovation is expected to emerge by presenting technology in fashion. Reflection on Innovation at several levels in the fashion system: is at the level of style, idealism and conceptual in production, technology and materials.

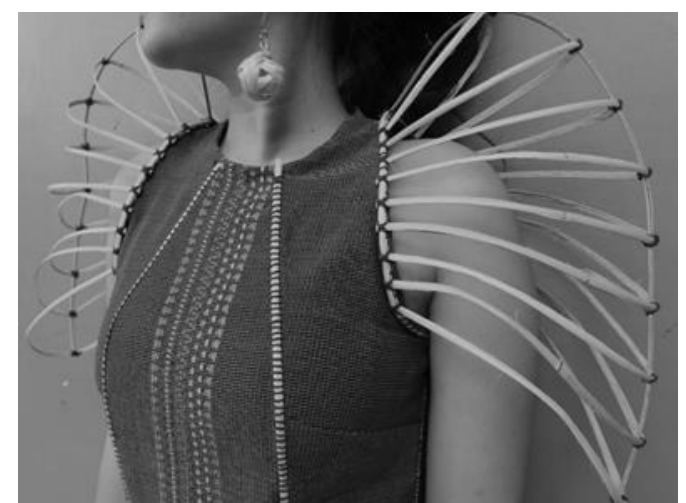

Fig. 2. The work of students creative concepts of Deconstruction, development to garment structure detail expose material.

The attitude of innovation can take two possible routes, the first is creative destruction in the sense of stagnation in old ideas in one's mind, trying to forget what is already there, by breaking the rules. While the second is creating spaces; or create newness of continuity. Attitude Creativity and innovation in the design of deconstructivism fashion are required to be possessed by learners as part of the future designer profession.

\section{Conclusion}

The fashion design approach by applying deskontractivism aesthetics is expected to increase activity and have more competitive substance values. In addition to demanding that learners understand design techniques that emphasize structural analysis, aesthetics that involve visual elements and more broadly can hone students' insight into fashion related to current issues, topic trends, both socio-political and cultural. In this case the learner must collect this information, interpret it by describing it in a concrete manner, analyzing every information, then interpreting it to do a combination of information to find a unified concept that will eventually lead to fashion work that is able to reflect personal character. In this case the learner is required to find information about his 'self' and the information obtained in relation to the 'global' environment. 
The search process by processing information obtained by investigating sources and conducting research and then conducting experiments. Deconstruction of clothing is to rebuild clothes by giving them a new aesthetic meaning. Construction is understood as a 'perfect' language setting. However, in the contemporary philosophy of deconstructivism, this is considered as a rejection of established aesthetics, so it needs to be reconstructed to find new aesthetic meanings through form studies.

The demands of creativity that are parallel to innovation are carried out on the awareness and desire for the need for the creation of new things. It is hoped that it can be used as an additive element as "opium" to continue to work in the creation of new things, so that each learner can display his best style. The ultimate goal of fashion creation is how fashion will deal with social and ecological consequences

\section{References}

[1] Almond, K. (2010) 'Insufficient allure: the luxurious art and cost of creative pattern cutting', International Journal of Fashion Design, Technology and Education, 3, pp. 15-24.

[2] Craft, A., Cremin, T., Burnard, P., \& Chappell, K. (2007) 'Teacher stance in creative learning: A study of progression', Thinking Skills and Creativity, 2(2), pp. 136-147.

[3] Departemen Perdagangan Republik Indonesia (2008) Pengembangan Ekonomi Kreatif Indonesia 2025. Jakarta: Departemen Perdagangan RI.

[4] Echeverri, D. (2015) 'Deconstruction as a structured ideation tool for Designers', In: Proceedings of the 3rd International Conference for Design Education Researchers, p. 870.

[5] Eckert, C., \& Stacey, M. (2001) 'Designing in the context of fashion-designing the fashion context', In: Designing in Context: Proceedings of the 5th Design Thinking Research Symposium, pp. 113-129.

[6] Fang, X. (2017) 'A Review on Deconstruction and Criticism', Comparative Literature: East \& West, 1, pp. 134-139.

[7] De Felice, Fabio., \& Petrillo, A. (2013) 'Key success factors for organizational innovation in the fashion industry', International Journal of Engineering Business Management, 5, pp. 5-27.

[8] Karpova, E., Marcketti, S., \& Kamm, C. (2013) 'Fashion industry professionals' viewpoints on creative traits and, strategies for creativity development', Thinking Skills and Creativity, 10, pp. 159-167.

[9] Kiziltunali, G. (2017) 'New frameworks in deconstructivist fashion: its categorization in three waves, application of the notions of plasticity, de-design and the inclusion of Bora Aksu and Hussein Chalayan as the third wave Turkish deconstructivist designers', Manchester Metropolitan University.

[10] Leclair, M. (2017) "Dior and I": understanding the combination of creativity and economy in fashion industry', Society and Business Review, 12, pp. 274-284.

[11] Loschek, I. (2009) When clothes become fashion: Design and innovation systems. Berg.

[12] Lubart, T. I. (2001) 'Models of the creative process: Past, present and future', Creativity research journal, 13, pp. 295-308.

[13] Ma, A. W. (2008) 'Computer Supported Collaborative Learning and Social Creativity: A Case Study of Fashion Design', Journal of Information, Information Technology \& Organizations, 3.

[14] McQuillan, H., Rissanen, T., \& Roberts, J. (2013) 'The Cutting Circle: How to Make Challenging', Designs Research Journal of Textile \& Apparel, 17.

[15] Robinson, J. R., Workman, J. E., \& Freeburg, B. W. (2018) 'Creativity and tolerance of ambiguity in fashion design students', International Journal of Fashion Design, Technology and Education, pp. 1-9.

[16] Romina, C., Anusca, F,. Kirsti A-M., \& Yves, P. (2010) 'Creative Learning and Innovative Teaching: Final Report on the Study on Creativity and Innovation in Education in the EU 
Member States. Luxembourg', Office des publications officielles des Communautés européennes (OPOCE), Institute for Prospective Technological Studies, Joint Research Centre, $n$ EUR).

[17] Shaheen, R. (2010) 'Creativity and Education', Online Submission, 1, pp. 166-169.

[18] Walker, R., \& Dell, S. (2008) 'Deconstructing fashion design: integrating theory and practice in design education', Social purpose and creativity-integrating learning in the real world, 48.

[19] Zborowska, A. (2015) 'Deconstruction in contemporary fashion design: Analysis and critique', International Journal of Fashion Studies, 2, pp. 185-201. 